\title{
Presencia y recepción del Brasil en publicaciones periódicas latinoamericanas: el caso de Claridad
}

María Marcela Aranda*

Resumen: A partir del estudio de publicaciones periódicas, fuente notable para comprender el dinamismo de los procesos históricos, nuestra intención es precisar y caracterizar la presencia y recepción del Brasil en la revista Claridad, que apareció en Buenos Aires entre los años 1926 y 1941. Se constata que el tema brasileño, en líneas generales, apareció tardíamente y fue producto del interés que el aprismo puso en dicho país en la década de 1930, cuando comenzó a acelerarse la turbulencia política y social. No obstante ello, la Tribuna del pensamiento izquierdista, como la llamara su director y fundador Antonio Zamora, ofreció el espacio para el debate acerca de las tensiones entre la vida política institucional del Brasil y los variados movimientos revolucionarios de esos años (Alianza Nacional Libertadora, trabahallistas, socialistas, tenentistas, comunistas, etc.), pero sin dejar de referenciar ambas dimensiones en el contexto general de las luchas antiimperialistas de la región.

Palabras clave: Brasil. Claridad. Discurso. Recepción. Teoría del contexto.

\footnotetext{
${ }^{*}$ Profesora Asociada Efectiva de Historia de las Ideas Políticas y Sociales de América y Argentina y de Historiografía Americana. Departamento de Historia. Facultad de Filosofía y Letras. Universidad Nacional de Cuyo. Argentina. E-mail: marcela.aranda06@gmail.com. Financiamento: Secretaría de Ciencia, Técnica y Posgrado, Universidad Nacional de Cuyo.
}

Anos 90, Porto Alegre, v. 21, n. 40, p. 363-387, dez. 2014 
Presencia y recepción del Brasil en publicaciones periódicas...

\section{Consideraciones preliminares}

Las publicaciones periódicas constituyen una fuente notable para comprender el dinamismo y la vitalidad de los procesos históricos. Toman el pulso de los tiempos a través del pensamiento de vanguardia que elaboran sus editores y colaboradores, y se anticipan a los giros claves que se producen en el ritmo histórico de cada sociedad. También justifican su presencia asignándose un espacio a sí mismas en el campo intelectual y estableciendo los límites entre su propia obra y otras tendencias; para convertirse en un notable archivo de datos y noticias, de atmósferas y sensibilidades que ilustran la inmediatez entre la elaboración y la difusión de ideas a través de múltiples perspectivas, contenidos heterogéneos y pluralidad de protagonistas (ZULETA, 1983; FERREIRA, 2005).

De esta manera, diarios y revistas, panfletos y manifiestos son algunas de las manifestaciones de la literatura y del pensamiento que se inscriben en esta clasificación general de publicaciones periódicas. A los efectos de nuestro trabajo, tomaremos la definición de Lafleur, Provenzano y Alonso (2006) sobre revista literaria entendiéndola como la exteriorización de un grupo, conjunto o cenáculo de intelectuales que buscan a través de sus páginas la difusión de su mensaje, libres de objetivos comerciales y, por lo general, al margen de la ayuda directa de sus gobiernos.

Ello nos permitirá adentrarnos en el estudio combinado de la dimensión material e histórica de la presencia y recepción del tema brasileño en la revista Claridad, que se editó en Argentina en el primer tercio del siglo XX. Como se sabe, para atrapar el significado de la historia, es preciso comprender las relaciones sociales entre los agentes presentes, y ellas forman parte de una realidad históricamente determinada. Es decir, que para entender la historia se deben interpretar las acciones humanas como partes constitutivas de una realidad social precisa. De allí que la producción de saberes en cualquier sociedad nacional no pueda permanecer aislada de los procesos de circulación internacional de teorías, individuos y modelos de acción política (NEIBURG; PLOTKIN, 2004). Al respecto, la historia de las ideas y la historia

Anos 90, Porto Alegre, v. 21, n. 40, p. 363-387, dez. 2014 
conceptual enriquecerán nuestro análisis, pues compartimos con Skinner (1985; 2002) y Koselleck (2009), la convicción de que el tiempo y las condiciones sociales transforman las palabras y ellas mismas producen cambios. En otros términos, la creatividad imaginativa, simbólica y material se enraíza en la elaboración conceptual y su historicidad.

Nuestro propósito es, entonces, identificar y caracterizar la presencia y recepción del pensamiento brasileño en la revista Claridad, en el período comprendido entre 1930 y 1940. Observamos que, entre otros tópicos, las preocupaciones sobre la política y la cultura en general - por ejemplo, la lucha antiimperialista, la figura de Luis Carlos Prestes, los rasgos autoritarios de los gobiernos de Getulio Vargas, las diferentes influencias étnicas en la conformación del pueblo brasileño, la literatura nacional -, hicieron visibles las conexiones ideológicas y las preocupaciones de los colaboradores brasileños y no brasileños de la revista. Claridad se editó en Buenos Aires entre los años 1926 y 1941 y:

[...] fue el testimonio de una etapa en la vida colectiva del continente, que se caracterizó por la búsqueda del apoyo popular y por el reconocimiento de la fuerza de la palabra, en un escenario en el cual irrumpía el poder de los medios gráficos de comunicación (FERREIRA, 1998, p. 21) ${ }^{1}$.

La revista publicó manifiestos políticos, gremiales y estudiantiles; analizó problemas de la región; comentó libros; intercambió publicaciones y receptó las polémicas que se dieron entre distintos partidos de izquierda en todo el continente. Además, destacó movimientos originales como el aprismo peruano, el cual intentó una versión americana del socialismo marxista. En todos los casos, la revista no impuso un criterio ideológico excluyente pues su misión era informar sobre el desarrollo de la izquierda en la Argentina y en América.

De hecho, la cuestión brasileña, en líneas generales, apareció tardíamente en Claridad y fue producto del interés que el aprismo puso en dicho país en la convulsionada década de 1930. No obstante ello, la Tribuna del pensamiento irquierdista, como la llamara el director 
y fundador de la revista, Antonio Zamora, ofreció el espacio para el debate acerca de las tensiones entre la vida política institucional del Brasil y los variados movimientos revolucionarios de esos años (Alianza Liberal, Alianza Nacional Libertadora, trabahallistas, socialistas, tenentistas, comunistas, etc.), sin dejar de referenciar estas dimensiones en el contexto general de las luchas antiimperialistas de la región. Como señala Teun Van Dijk:

No es la situación social "objetiva” la que influye en el discurso, ni es que el discurso influya directamente en la situación social: es la definición subjetiva realizada por los participantes de la situación comunicativa la que controla esta influencia mutua (2012, p. 13, subrayado por el autor).

Sin embargo, a partir de 1930 el tono de la lucha antiimperialista adquirió otra intensidad en las páginas de la revista. La buena vecindad de Franklin Delano Roosevelt (1933-1936) impactó favorablemente en la región, pues al principio de la no intervención le sumó la perspectiva de una recuperación económica simbolizada en el New Deal, lo que lo convirtió "[...] en un modelo posible para varios sectores, aún los de la izquierda" (FERREIRA, 1998, p. 29). Desde ese momento, Claridad se abrió al debate sobre las posibilidades democráticas para el continente, en medio de la eclosión de la Guerra Civil Española y de los preparativos de la Segunda Guerra Mundial. La revista se transformó y a partir de su número 307, aparecido en 1937, pasó a llamarse La Revista Americana de Hombres Libres. Más allá de estos avatares, que se tradujeron en las diversas etapas de la revista Claridad, lo sustancial es que no hubo diferencias marcadas entre ellas, en especial porque su director fue siempre Antonio Zamora y porque el espíritu que animaba a éste y a sus colaboradores era el de generar una crítica aguda y elevada acerca de los problemas de la época, los cuales, enfocados desde Buenos Aires, se descentraban "[...] con el objetivo de trabajar por la democracia y la unión de las Américas" (FERREIRA, 1998, p. 32). 


\section{Brasil, una historia singular y compartida en Iberoamérica}

Brasil se independizó de la monarquía portuguesa en 1822, acuñando una larga tradición de lengua, cultura y hábitos intelectuales, sociales, políticos y religiosos ciertamente peculiares en la región. Luego constituyó un imperio, con una nobleza y una oligarquía de terratenientes, dueños del poder económico y político que dominaban una sociedad esclavista. Durante el siglo XIX, el país alcanzó ingentes riquezas y un desarrollo material que ningún otro país americano había conseguido hasta el momento. Brasil era consciente de su presencia en América y en el mundo gracias también a la fortaleza de las instituciones sociales heredadas del imperio. Esta fuerza económica y militar pudo dominar e integrar su territorio y, en especial, desarrollar sus riquezas agrícolas, ganaderas, mineras e industriales.

En 1889 el imperio dejó paso a la república y, con ésta, la abolición de la esclavitud. La crisis de muchos hacendados se superó porque la riqueza del azúcar, el algodón y el café en el norte fue completada por la explotación del café, la ganadería y las industrias en el sur, y más tarde por el auge del caucho en el Amazonas. De esta manera se consolidó el poder económico del Brasil.

Entretanto, en el gobierno nacional y estadual, el ejército y la marina intervinieron en revueltas y guerras civiles, imponiendo líderes y zanjando todo tipo de conflictos sociales y políticos. La emergencia de la república hizo disolver los partidos monárquicos liberal y conservador; pero no significó que se constituyera un partido nacional. Por el contrario, los gobernantes, de origen paulista o minero, sacrificaron los intereses nacionales a favor de los intereses imperialistas y superaron, en más de cinco veces, el total de empréstitos que había contraído la monarquía. Durante los años de la república velha (1889-1930), los capitales extranjeros se adueñaron de los servicios públicos del país (electricidad, transportes, desagües, teléfono, gas, electricidad) y organizaron trusts en la industria y la agricultura. 
Una constitución de corte centralista reforzó la autoridad del poder ejecutivo en estos primeros años (Manuel Campos Salles, 18981902) y se ordenaron las finanzas, se finiquitaron pleitos territoriales con los países vecinos y se facilitó el desarrollo social, económico y cultural. Las siguientes presidencias de Francisco de Paula Rodrigues Alves (1902-1906) y Alfonso Penna (1906-1909) siguieron este impulso. Sin embargo, durante las gestiones de Hermes da Fonseca (1910-1914), Wenceslao Bras (1914-1918), Epitacio da Silva Pesoa (1919-1922), Artur Bernardes (1922-1926) y Washington Luis Pereira de Souza (1926-1930) volvieron algunos conflictos que ya habían sacudido al Brasil. Primero, el apoyo de las fuerzas armadas hacia líderes con aspiraciones políticas (Hermes da Fonseca enfrentado a Ruy Barbosa, fundador del Partido Liberal en 1910), lo cual provocaba violentos choques y consolidaba la autoridad del poder ejecutivo. La economía, en segundo lugar, porque el ritmo zigzagueante de los precios internacionales del caucho y del café repercutía en la situación del Brasil, que superaba las crisis gracias a los empréstitos, la aceptación de las industrias extranjeras, la llegada de miles de inmigrantes y la relativa bonanza de la primera guerra mundial.

Sin embargo, el sistema político y social tenía sus fisuras. Las luchas por el poder continuaban, pero, como en otros países de la región, llegaron las nuevas tendencias ideológicas representadas en la revolución mexicana de 1910 y la revolución rusa de 1917. Al mismo tiempo, las nuevas generaciones de la clase media se resistían al poder de las oligarquías brasileñas y reclamaban una participación que las fuerzas tradicionales no les concedían. Uno de los núcleos donde esto se manifestó con fuerza fue en el seno de las fuerzas armadas, de variada composición étnica y social y, por ello, ajeno al espíritu de casta. La oficialidad joven era permeable a las nuevas ideas y su conciencia de la imprescindible integración regional del país crecía a la par que los diversos y distantes territorios y grupos no aceptaban la brújula general del sistema político, al cual responsabilizaban de la injusticia social y económica y de la falta de un auténtico espíritu nacional. ${ }^{2}$

Uno de estos grupos provocó, sucesivamente, una serie de revueltas conocidas como la revolución de los tenientes, en razón del grado militar de sus impulsores, en los años 1922 y 1924. Invocaban 
un programa democrático y nacionalista a través del lema "republicanizar la República”, pero fueron reprimidas sangrientamente. Los sacrificios de sus protagonistas cayeron en terreno abonado, cuando el 28 y 29 de octubre de 1924, un oficial de la división de ingenieros, Luis Carlos Prestes, que ya había estado en los movimientos iniciales, lideró otra sublevación militar (AMADO, 1958; SACCHI, 1971; NOBLE, 2007).

Bajo su dirección se organizó la marcha de la Columna de Prestes, que se propuso atravesar todo el Brasil desde el norte (Matto Grosso) hacia el sur para apoderarse, finalmente, de Río de Janeiro, sede del gobierno nacional. Este periplo recorrió más de 35.000 kilómetros y terminó dispersándose en territorio boliviano hacia 1927. Un año después Prestes se trasladó a la Argentina, donde trabajó como ingeniero en Rosario y Buenos Aires. Allí conoció al comunista paraguayo Oscar Creydt y se relacionó con los socialistas Rodolfo Ghioldi y la Liga Anti-imperialista. Repudió el golpe cívico-militar que se produjo en la Argentina el 6 de setiembre de 1930 y desde Montevideo adhirió al Partido Comunista del Brasil, tras lo cual se tbrasladó a la Unión Soviética, donde vivió tres años y se casó. En 1935 regresó a su país para actuar en política.

Entretanto, los anarquistas brasileños se habían dividido luego de los sucesos revolucionarios rusos de 1917. Octavio Brandao, Astrogildo Pereira, Antonio Canella y Roberto Morena habían fundado, en 1921, el Partido Comunista y publicaban los periódicos La clase obrera y Movimiento comunista. Se enfrentaron a los anarquistas en el movimiento sindical y, con Sarandy Reposo, organizaron la Confederación Sindicalista Cooperativista y en 1927 el Bloque Obrero y Campesino, que se presentó a elecciones comunales. Pero los enfrentamientos internos con los trotskistas habían debilitado su fuerza política.

$\mathrm{Al}$ aproximarse el año 1930, las condiciones estaban dadas en Brasil para el estallido de una nueva revolución. El pacto de dominación oligárquica se había roto y con su fragmentación, se produjo la diversificación del sistema político partidario, en especial con la articulación del tenentismo y los disidentes oligárquicos y la aparición de partidos democráticos estaduales y del partido democrático nacional, definidos como un frente de oposiciones regionales. Los cambios 
generados por la industrialización y la urbanización tampoco eran compatibles con este modelo político-social-económico, que se vio afectado por la crisis de 1929. Como dice Waldo Ansaldi, estaba en crisis la idea de democracia liberal, cuya principal certeza era que sólo tenía una aplicación formal en la región, y tanto revolucionarios como reaccionarios rechazaban esta formalidad. ${ }^{3}$

El detonante de este movimiento de fuerza fueron las elecciones presidenciales de ese año. En octubre de 1930 ascendió al poder Getulio Vargas, quien convocó a una Asamblea y fue elegido presidente constitucional desde 1934 hasta 1938. Vargas pertenecía a la llamada generación de 1907, que reunía a abogados, cercanos familiarmente a los coroneles, con experiencia política exitosa, y apoyados por los tenientes, y entre los cuales se destacaban, además, Osvaldo Aranha, Lindolfo Collor, Flores da Cunha y Paim Filho. Su objetivo era corregir los excesos políticos del presidente Washington Luis Pereira y restaurar la pureza republicana. Sin embargo, la nueva etapa estuvo signada por el protagonismo excluyente de Getulio Vargas que entre 1937 y 1945 lanzó el Estado Novo y, tras el interregno del general Eurico Gaspar Dutra (1945-1951), retornó a la presidencia hasta 1954, cuando puso fin a su vida, suicidándose.

Brasil comenzaba el segundo tercio del siglo XX en un escenario delimitado por la importancia asimétrica de sus grupos sociales. Mientras los artífices de los cambios estructurales pertenecían a la oficialidad del ejército, otros nuevos sujetos sociales - clase media, burgueses y trabajadores industriales y de servicios - demandaban la participación política y la transformación social y económica que los excluía históricamente. Pero estas demandas eran antagónicas, pues democracia política y democracia social eran términos excluyentes. No obstante que la crisis de la dominación oligárquica intentó ser superada por una política de corte populista, según Ansaldi ésta se prolongó hasta la presidencia de Joao Goulart en 1964 y no alcanzó a construir un sistema hegemónico.

En el terreno ideológico, esta época vio desarrollar tendencias autoritarias y antiliberales tanto en Europa como en América Latina, lo que se manifiesta en las obras de los brasileños Alberto Torres, Oliveira Vianna, Azevedo Amaral y Francisco Campos. En el 
escenario brasileño, la confrontación se dio entre tres líneas ideológicas de sesgo autoritario: el tenentismo, el integracionismo y el estadonovismo (ANSALDI, 2003). En el primer caso, su proyecto industrializador con intervención del Estado, garantista de los derechos de los trabajadores y defensor de la pequeña propiedad - programa presente en la revolución de 1930 - era una estrategia de defensa militar y de oposición a los intereses de los cafetaleros, antes que una genuina apuesta económica nacional. Hacia 1933, se produjo la pérdida gradual del control político tenentista en Sao Paulo y Minas Gerais y continuaron las prácticas republicanas oligárquicas. La constitución de 1934 recogió estas demandas de intervencionismo estatal respecto de los recursos naturales, el desarrollo económico y la regulación del mercado laboral; pero sólo fue una síntesis entre confrontación y compromiso.

En este marco de indefinición sobre el protagonismo político del poder militar o del poder civil, la centralización o la descentralización, la ampliación o la reducción de la ciudadanía política y social, la autonomía de los sindicatos o su sujeción al Estado, proliferaron los partidos estaduales que buscaban articular las diferentes demandas. Así surgieron la Alianza Integralista Brasileña (1932) y la Alianza Nacional Libertadora (1935). Ambas captaron los elementos tenentistas en disolución, pero mientras la primera se declaró filofascista y conservadora, la segunda adhirió al comunismo y propició la movilización de las masas. La filosofía del integralismo era ecléctica y en ella confluían elementos del nacionalismo telúrico, el mesianismo místico sobre el destino histórico de la nueva raza mestiza, el tradicionalismo social y religioso de raigambre portuguesa (Salazar), el corporativismo fascista y el antisemitismo alemán. Igualmente apeló a la movilización y organización de la clase media y trabajadora. Por su parte, la Alianza Nacional Libertadora fue estructurada a partir del ala legalista del Partido Comunista y del liderazgo de Luis Carlos Prestes quien, como señalamos, ya había regresado al país. Algunos autores la definen como una estrategia de Frente Popular que reclamaba la nacionalización de las empresas extranjeras y la liquidación de los latifundios. Otros, en cambio, sostienen que se trató de un bloque antimperialista de clases bajo iniciativa del proletariado y 
el tenentismo. De todos modos, creció en la confrontación con el integralismo. Finalmente, el Estado Novo propiciaba un autoritarismo paradójicamente desmovilizador.

La presencia de Vargas en la historia contemporánea del Brasil fue decisiva. Comenzó con un fuerte programa nacionalista y antimperialista, con medidas de marcada justicia social y de beneficios populares que consolidaron su prestigio político. Reunió a viejos compañeros de Prestes, a revolucionarios y nacionalistas y persiguió a sus enemigos, acusándolos de comunistas y fascistas. En 1935, Prestes se opuso a Vargas, desde la Alianza Nacional Libertadora, a quien tildó de fascista. Esto coincidió con la existencia de un ambiente caldeado que buscaba solución a serios problemas sociales, y el partido comunista había lanzado la consigna del Frente Popular, siguiendo las directivas soviéticas e incluyendo a poderosos sindicatos obreros. Tenía un programa revolucionario: suspensión del pago de la deuda externa, expropiación de tierras, reforma agraria, control estatal de los bancos, reformas laborales y religiosas; y fueron protagonistas de huelgas violentas.

Mediante la Ley de Seguridad Nacional (1935), Vargas proscribió a la Alianza Nacional Libertadora y ordenó una severa represión policial en Natal y otros puntos del país, con lo cual se desarticularon las organizaciones de izquierda y se encarcelaron a políticos, civiles y militares descontentos. Entretanto, el presidente recibía la ampliación de los poderes especiales. Sin embargo, Prestes proclamó la rebelión armada y fue nombrado presidente "honorífico" del Brasil, con el apoyo de las guarniciones de Río de Janeiro, Río Grande do Sul y Pernambuco. El gobierno se impuso a los revolucionarios y encarceló a Prestes y sus principales seguidores: Domingo Velasco, Abguar Bastos, Joao Mangabeira, Ottavio de Silveiro y Hercolino Cascardo. Prestes fue condenado a dieciséis años de prisión y el argentino Rodolfo Ghioldi a cuatro años.

No obstante lo ocurrido, esta derrota no significó el fin de la actividad de izquierda en el Brasil. El Partido Comunista y otras agrupaciones continuaron en la lucha sindical y electoral y mantuvieron con fervor las consignas ideológicas antifascistas internacionales, las que prevalecieron, al menos, hasta el final de la era de Vargas, quien amnistió a Prestes en 1945. 


\section{Presencia y recepción del Brasil en la revista Claridad}

Como se ha expresado, Claridad fue una publicación que atravesó varias etapas, pero a los efectos de nuestro trabajo, interesan las dos últimas: una, entre julio de 1926 y julio de 1939, y la otra, entre esta última fecha y diciembre de 1941, cuando, por motivos de financiamiento, Antonio Zamora se vio obligado a cerrar este emprendimiento editorial. Los formatos de la revista también sufrieron alteraciones con el tiempo: tipografía, cantidad de columnas de texto, tamaño de las páginas, incorporación de fotos e ilustraciones, nuevas secciones; llegando inclusive a aumentar la frecuencia de salida, que terminó siendo semanal (FERREIRA, 2005).

Hasta 1938, la atención se centró en la divulgación literaria; pero a partir de ese año se incorporaron cada vez más artículos de carácter político y social. En un ambiente enardecido por las discusiones teóricas y metodológicas acerca del porvenir político de las izquierdas en América Latina, el director de Claridad decidió incluir la opinión de hombres de diferentes matices de la postura liberal, democrática y revolucionaria, pues entendía que eran útiles para discernir "los problemas de la izquierda de nuestra época" (ZAMORA, 1939). ${ }^{4}$ También se publicaron periódicamente suplementos especiales consagrados "[...] a dilucidar los problemas de la realidad contemporánea". 5

En cada época, la revista receptó la presencia de iberoamericanos y, en especial, de los refugiados de otras latitudes que se encontraban en la Argentina. La colaboración de chilenos, peruanos, bolivianos, mexicanos, uruguayos fueron reflejando las problemáticas nacionales en Claridad, siempre con una proyección de solidaridad continental en sus juicios y valoraciones. En tal sentido se debe justipreciar la presencia de artículos de opinión, notas y colaboraciones de brasileños y extranjeros sobre cuestiones políticas, sociales, económicas y culturales del propio país. En la clasificación que Eduardo Devés Valdés (2000) ha efectuado sobre el pensamiento latinoamericano, esta etapa - contextualizada entre las dos guerras mundiales - correspondía a un tercer momento dentro del proyecto identitario y tenía que ver con la reivindicación de la economía iberoamericana, la cual coexistió con el enfoque cultural basado en el

Anos 90, Porto Alegre, v. 21, n. 40, p. 363-387, dez. 2014 
carácter latino y el social, a través de la defensa del mestizaje, fuese indigenista o afroamericano. No obstante que el énfasis económico lo adoptaron tendencias de la izquierda y la derecha, fue contundente el rechazo a las formas de penetración de las potencias en el interior del continente, rasgo que fue configurando el clima antiimperialista de la época.

Para este trabajo, seleccionamos un corpus de diecinueve artículos que Claridad publicó entre 1930 y 1941. La mayoría de los autores es de nacionalidad brasileña, y entre ellos se destacan: Luis Carlos Prestes, Elio Colle, Barbosa Mello, Domingo José Martins, Pedro Motta Lima, Octavio Mangabeira y Monteiro Lobato. También los hay de procedencia peruana (Luis Heysen), boliviana (Oscar Cerruto), argentina (Bernardo Kordon y Adolfo Vázquez-Gómez) y española (Campio Carpio).

No obstante que el tema brasileño comenzó a aparecer en la revista a partir de los años 1930, recién en el suplemento $\mathrm{N}^{\circ} 343$ de julio de 1940, Domingo J. Martins manifestaba explícitamente la importancia que Claridad venía otorgando, desde hacía diez años, a la “[...] situación excepcional en que se encuentra el Brasil, sometido a una de las dictaduras más retrógradas del mundo”. Reconocía el valor documental de las notas y colaboraciones que aparecieron en los diferentes números de la revista, y que permitían explicar la condición del país como un "[...] pueblo sojuzgado, de nación inorgánica sometida a un despotismo sin control que la desintegra destruyendo su arquitectura estatal, reducida, en suma, a la barbarie". Además, redoblaba el llamado "a los pueblos indoamericanos", advirtiendo "[...] el peligro que se cierne sobre la independencia del Brasil [...]" e insistiendo en "[...] la premura y la congoja del riesgo que su caída apareja para el resto del Continente" (MARTINS, 1940, p. 255).

Si bien ésta fue una de las cuestiones centrales que se trataron en Claridad, otro asunto de vital interés fue la acción revolucionaria del teniente Luis Carlos Prestes, figura importante de la política brasileña, y de su partido, la Alianza Nacional Libertadora. Las tensiones entre el varguismo, el integralismo y las fuerzas de la izquierda aliadas con el tenentismo, se manifestaron notablemente en la publicación. Así, en 1938, Barbosa Mello denunciaba el régimen de Vargas como 
"fascista, corporativo y totalitario en proceso de consolidación" y lamentaba que el país se debatiera "[...] en las contradicciones creadas por un régimen que se ha instaurado sin una base de masa”. En tono suspicaz, subrayaba la vacilación de algunos sectores de la izquierda frente a la lucha de Vargas con los integralistas y sus asociados, por aceptarla "como el inicio de una lucha contra el fascismo internacional"; cuando, en realidad, aquellos debían esperar medidas concretas del Estado para desafiar al imperialismo.

Un año después, Martins (1939) censuraba las tácticas de acercamiento de algunos comunistas e integralistas al gobierno varguista para conseguir su favor oficial, en especial los primeros que denunciaban a la Alianza Nacional Libertadora para mantenerla desmantelada y desorganizada, mientras sus líderes sufrían persecuciones y debían marchar al exilio. Entre las medidas consideradas "indignas" estaba el Servicio de Encuestas Políticas y Sociales que, a juicio del autor, representaba "una de las más elocuentes manifestaciones de la servil sujeción espiritual y material de la casta gobernante de Brasil a los sangrientos sistemas totalitarios europeos, y como una ofensa a la tradición libre y democrática de América".

En el mismo tono, el aprista boliviano Oscar Cerruto (1939), observador de la política americana y brasileña, alertaba sobre una posible dictadura militar, refiriéndose a la inestabilidad de los sectores internos que sostenían a Vargas. El panorama se completaba con un recorrido por la actualidad política de la Argentina, Bolivia, Colombia, Cuba, Chile, Ecuador, Haití, México y Perú.

Luego, apareció en la revista un artículo sobre el presente y el pasado brasileño, firmado por Adolfo Vázquez-Gómez (1941), que recalcaba el ejercicio autoritario del poder por parte de Vargas, mediante la censura de la libertad de expresión y la coerción física y la represión sobre personas e instituciones que, en funciones periodísticas, intelectuales o legislativas, mostraban su disconformidad ideológica con el régimen. El autor también celebraba la transcripción que el Jornal do Commercio había hecho del reportaje que La Vanguardia había realizado a Alfredo Palacios, en ocasión de ser consultado por una de las tantas constituciones varguistas que había tenido el país. Éste sentenciaba que el único antídoto contra el mal autoritario era 
"la ampliación y el ennoblecimiento de la democracia" para que la política dignifique la vida del hombre y le proporcione la libertad "[...] sin la cual es despreciable la vida".

También en 1939, Claridad publicó una carta del ex canciller brasileño, Octavio Mangabeira, dirigida al ministro de guerra de Vargas, general Eurico Gaspar Dutra, que había sido editada primero en A Democracia, el órgano de los exiliados brasileños en Riera, Uruguay. Mangabeira desconocía las razones de su prisión en el Hospital de Policía Militar de Río de Janeiro, pero reconocía la importancia de no guardar silencio en aquella "hora tan penosa de la Historia del Brasil", ante las tropelías de un gobierno que recluía en prisión "[...] a un brasileño que piensa en su patria y que habla como piensa, no en conciliábulos, sino a las claras y sin eufemismos a la más alta autoridad del Ejército”.

El tono de estas líneas se comprende si se contextualiza en el espíritu de discusión ideológica de las izquierdas en América Latina y, especialmente, en torno a la cuestión de la lucha antiimperialista. En efecto, el primer artículo sobre el tema brasileño fue escrito por el peruano aprista Luis Heysen, quien a mediados de 1930 seguía denunciando la penetración imperialista en la región y convocaba a los trabajadores manuales e intelectuales del Brasil a sumarse y definirse en la lucha antimperialista junto con los demás trabajadores de los otros países indoamericanos. Convocaba a una empresa continental y calificaba de "soldados" del APRA a aquellos países que comprometían sus fuerzas logísticas y estratégicas en la lucha "por la defensa y la organización de la Alianza" en el Brasil, entre ellos Costa Rica, Haití, Puerto Rico, San Salvador, Cuba, Panamá, México, Perú, Bolivia y Argentina. En el siguiente número de la revista, sostenía que el imperialismo era fruto del continum histórico y que había producido, en consecuencia, el antimperialismo. El APRA era definido "como partido de frente único, nacional-latinoamericano, autónomo, antiimperialista", que defendía un "plan doctrinario" para resolver "nuestros problemas político-económico-sociales libertándonos de la tiranía de dentro en complicidad con la conquista de fuera". Urgía a definir los métodos para "antiimperializar la conciencia de las clases oprimidas", desde un criterio local, es decir "[...] ligado a la realidad dependiente y determinante". Finalizaba 
afirmando que el mejor ejemplo para América Latina era la India revolucionaria de Gandhi.

Sin embargo, la personalidad más destacada en el movimiento revolucionario brasileño era la de Luis Carlos Prestes, por sus vinculaciones con el ejército y con la izquierda de Brasil. Como se sabe, había encabezado la famosa columna revolucionaria que llevó su nombre, "Columna de Prestes", había estado exiliado en Buenos Aires y había adherido al Partido Comunista. En opinión de Prestes, los sucesos revolucionarios que se estaban sucediendo en Brasil requerían la acción conjunta de todos los sectores de la izquierda, consigna que se impulsaba desde Claridad. En sus páginas, Prestes advertía la manipulación del uso de la palabra revolución "para empañar groseramente a las clases trabajadoras", encubriendo, en su lugar, las influencias imperialistas presentes en la conformación de la Alianza Liberal que había llevado a cabo la revolución de 1930 y había puesto fin a la república velha. En un lenguaje franco, directo y sugestivo, pedía que los campesinos, obreros, soldados y marinos capitalizaran la experiencia histórica acumulada en el Brasil para confraternizar en un "gobierno único", con el fin de satisfacer las necesidades de todos los sectores y luchar "con intransigencia contra los imperialistas". "La tierra para el que la trabaja", afirmaba contundentemente.

Varios años después, en 1935, Prestes regresó a su país y emprendió una acción revolucionaria en contra del gobierno de Vargas. En esa oportunidad publicó un manifiesto a los trabajadores del Brasil, convocando a una Alianza Nacional Libertadora, como única posibilidad política "popular, anti-imperialista, anti-feudal y anti-fascista". En las marcas de su lenguaje, la traición de ellos y la lealtad de nosotros aparecían claramente delimitados: "[...] de un lado, los que quieren consolidar en el Brasil la dictadura fascista, liquidar los últimos derechos democráticos del pueblo y acabar la venta y esclavización del país al capital extranjero [...]", junto al integralismo "como brigada de choque de la reacción"; mientras, "[...] del otro lado, todos los que, en las filas de la ANL, quieren defender de todas maneras la libertad nacional del Brasil, pan, tierra y libertad para su pueblo". Además, iba prefigurando la intención de conformar un Frente Único - estrategia adoptada por el $7^{\circ}$ Congreso de la Tercera Internacional - que no distinguía "privilegios de raza, de color o 
de nacionalidad" para abarcar una lucha por la libertad e igualdad, deuda que la sociedad brasileña tenía, por ejemplo, con la población negra, desde sus comienzos colonizadores.

Sin dudas que el avance de la "Columna de Prestes" fue una de las hazañas destacadas en las páginas de Claridad. En primer lugar, se le asignaba un lugar destacado en el desarrollo histórico del país, sobre todo, en las luchas por la igualdad, la participación socio-económico-política y el acceso a los beneficios de la modernidad, cuya carencia habían comenzado a denunciar amplios sectores de la población desde fines del siglo XIX: campesinos, trabajadores de la ciudad, oficialidad joven del ejército, grupos oligárquicos que no participaban de las prerrogativas de los gobiernos estaduales y del gobierno federal, intelectuales, negros, indígenas. El país contaba con una larga tradición de aprendizaje en este tipo de reclamos, en los que, a veces, se sumaban importantes elementos místicos y psicológicos. ${ }^{6}$

En segundo lugar, se exaltaba la figura de Prestes como síntesis heroica que " $[. .$.$] se identifica en la conciencia de todos los sinceros$ y auténticos luchadores contra la opresión de América Latina". Así, desde la tribuna de Claridad, Juan Vargas (1935) le adjudicaba el rol de líder, es decir "[...] figura romántica y legendaria de un caudillo moderno de las masas oprimidas de estos países encadenados y hundidos por el imperialismo y sus venales burguesías nacionales". Detallaba el minucioso recorrido de Prestes y sus hombres, "por selvas y pampas", "por ciudades y pueblos", internándose en el Paraguay y dispersándose, finalmente en Bolivia, en 1927, no sin antes librar victoriosas batallas e imponer una disciplina rigurosa pero entusiasta. En opinión del autor, hacia 1931, Prestes ya había evolucionado en su condición de pequeño burgués hacia revolucionario de izquierda y condenaba a su anterior clase por vacilante y contrarrevolucionaria. Esta evolución del pensamiento, finaliza el autor, era "una lección" para quienes pretendían alcanzar "la liberación latinoamericana" negando al proletariado y recurriendo al reformismo parlamentario. En esta exposición, que incluía la biografía intelectual de Prestes, se subrayaba su adhesión al marxismo-leninismo, adoptado en su viaje a Rusia, y con el cual identificaría su posterior lucha política al regreso a Brasil, para enfrentarse al gobierno autoritario de Vargas. 
No obstante este protagonismo de Prestes, no todos los revolucionarios brasileños debían considerarse comunistas, como lo señalaba el periódico Señales, a través de textos que reproducía Claridad. La misma Alianza de Prestes estaba compuesta por militantes de numerosas organizaciones: Partidos Socialistas, Trabahillistas, Tenientistas, Comunista, Alianza Liberal, organizaciones culturales, centros deportivos, agrupaciones de intelectuales y artistas, ligas antifascistas, ateneos liberales, sindicatos obreros y profesionales, quienes, como hemos señalado, habían elegido presidente al general Luis Carlos Prestes.

Unos años después, otro artículo escrito por Martins (1939) insistía en la presencia singular de la Alianza de Prestes en el escenario nacional y continental. Tras una periodización clásica de la historia del Brasil, definía a Prestes como "primus inter pares de los cadetes de la Escuela Militar de su tiempo", es decir un personaje con talento para conducir y dirimir con claridad y astucia las tensiones que enfrentaban a los grupos antagónicos en su época. El autor adjudicaba a la marcha de Prestes la capacidad de haber despertado la conciencia democrática del pueblo brasileño y que, aún cuando las intenciones de Vargas estaban solapadas bajo ropajes republicanos, las acciones del teniente habían conseguido insuflar en su pueblo "la exigencia de la verdad electoral, la dignificación de justicia y el respeto al régimen democrático".

En otro artículo escrito por Elio Colle (1938), se afirmaba que Brasil estaba asistiendo a una invasión ideológica y política del fascismo y de los japoneses, a través de su poder económico. En ese contexto, la situación del país no difería del resto de América Latina y exhortaba a que estos se aprestaran "a una lucha efectiva por la liberación integral de sus países".

Por su parte, en una nota de Campio Carpio (1939), se exponía un desarrollo de la historia contemporánea del Brasil, donde se subrayaba la función de los grupos revolucionarios en la década de 1930. Según este autor, la política brasileña padecía la distorsión que el imperialismo había introducido en las sociedades políticas americanas, en especial la trata de negros y la consolidación de las oligarquías regionales en el siglo XIX. A juicio de Carpio, Vargas había trabajado a favor de la reacción y en contra de las fuerzas progresistas.

Anos 90, Porto Alegre, v. 21, n. 40, p. 363-387, dez. 2014 
Como reflejo de la apertura que se reflejó en la última etapa de Claridad, Pedro Motta Lima (1938) publicó un artículo subrayando la importancia ideológica del ingreso de Osvaldo Aranha en el gobierno de Vargas, pues su definición democrática podía significar una garantía de que el Brasil no permitiría el predominio fascista. De todos modos, el autor se iba a explayar largamente en los motivos que definían al gobierno varguista como fascista.

Por último, el escritor argentino Bernardo Kordon, conocedor de la historia y de la literatura brasileña, por haber vivido largo tiempo en aquel país, analizó los aspectos históricos y sociales de la raza negra en el Brasil, que él notaba visibles en la conservación de los patrones culturales definidos por el sistema patriarcal, la producción agrícola, las condiciones geográficas y sociales del Brasil colonial.

\section{A modo de conclusión}

Quentin Skinner afirma que las opiniones, argumentos y juicios de los autores no deberían ser interpretados en el "cielo" de las ideas, sino en el contexto histórico-particular en el que surgen. Esto significa que al entablar el diálogo con el pasado, debemos tener en cuenta la distancia entre sus mundos intelectuales y el nuestro. Las tesis, los argumentos y la retórica desplegada por los autores deben ser leidos como actos de lenguaje que producen o quieren producir efectos sobre un público determinado, pues forman parte de una visión del mundo, una ideología o un sistema de pensamiento y un conjunto de gestos políticos (NADEAU, 2009).

Reinhardt Koselleck insiste en rescatar los lugares y los objetos de la historia que permiten reconstruir una historia social de los conceptos. Su interés está puesto en mostrar históricamente, y con el apoyo de pruebas documentales, cómo ciertos conceptos aparecen en el momento en que son reivindicados por una sociedad determinada y para ella misma. Si el uso de un concepto determina su sentido, los usos (pasado y presente) de un concepto determinan sus usos posibles.

Entonces los contextos socio-históricos son horizontes de sentido para los autores del pasado, pues cuando estos utilizan un 
concepto particular, su uso depende de los sentidos posibles que le concederán los diferentes receptores. De tal modo que para comprender cabalmente la revista Claridad, precisamos conocer los resortes de la política europea, estadounidense e iberoamericana que con ella dialogaron. Pues los conceptos son herramientas de la historia que se va construyendo, no de forma independiente de los hechos históricos, sino en interpelación con ellos. En tal sentido, los términos despojo, penetración, explotación fueron experimentados por los agentes sociales iberoamericanos de la primera mitad del siglo XX como formas de agresión que ellos percibían en la acción de los países ricos y de sus compañías particulares. La convergencia de este nacionalismo económico o continentalismo fue compartido también por figuras de otras latitudes, tales como José Vasconcelos (mexicano), Gabriela Mistral (chilena), Federico Henríquez y Carvajal (dominicano), Vicente Sáenz, Mario Sancho y Carmen Lyra (costarricenses), Jorge Eliécer Gaitán (colombiano), Rodolfo y Julio Irazusta (argentinos), Froilán Turcyos (hondureño), José Peralta (ecuatoriano), Augusto César Sandino (nicaragüense), a través de una literatura de denuncia y aleccionamiento a las mayorías trabajadoras y desposeídas.

La cuestión brasileña estuvo presente en la publicación desde una perspectiva omnicomprensiva mayor, que fue la presencia imperialista y su correlativa lucha antiimperialista, las analogías con el totalitarismo nazi-fascista, el ejercicio de la libertad y la democracia y la recepción de las ideas de la izquierda en el escenario político, social, económico y cultural de Iberoamérica. En los casi veinte artículos analizados, que comprenden los años 1930 a 1941, los autores desplegaron un relato contundente, dramático, cuya marca lingüística es performativa. Los conceptos advierten, apelan y conforman mensajes que se constituyeron en el medio por excelencia para contribuir a la modificación de la conciencia de los lectores.

En esta empresa de recuperación y fortalecimiento de la tradición democrática en nuestras sociedades, con especial referencia al Brasil, fue posible advertir el peso que la conciencia histórica americana de esa época le había otorgado a determinados hechos. Todos los países que fueron objeto de estudio y discusión en las páginas de Claridad, se habían caracterizado, en su conformación 
social, por la inicial vertiente mestiza (biológica y cultural), a la cual le sumaron el notable aporte inmigratorio europeo y asiático, entre fines del siglo XIX y primera mitad del siglo XX. Las dos guerras mundiales también se reflejaron en las tensiones, contradicciones, antagonismos y conflictos que animaron a esas sociedades. La revista participó de estas reverberaciones históricas y facilitó el espacio para el desarrollo de un diálogo analítico y plural entre los izquierdistas europeos que se refugiaron en América, los que quedaron en el viejo mundo y los nuevos adeptos locales que ganaban para su causa de lucha y sacrificio.

Las páginas de la revista fueron, entonces, la "tribuna" desde donde se instruía a los lectores sobre la teoría y praxis de sujetos e instituciones con responsabilidad directa sobre los destinos de la población. Por ello se utilizaba un lenguaje llano, que remitía con claridad a los textos de los autores clásicos (Marx, Lenin, Trotsky, Bakunin, Stalin). Pero, sin pretender transplantar patrones de conducta social, política y económica nacidos en otras latitudes, el propósito de los autores estaba centrado en adaptar el acelerado desarrollo ideológico de Europa a las reales condiciones socio-históricas vigentes en América. El mismo Antonio Zamora era un ferviente militante del partido socialista argentino, al cual consideraba una fuerza política con capacidad para transformar la sociedad.

Sin dudas que el aprismo fue el mejor ejemplo ilustrativo de esta tendencia, pues se trató de un frente policlasista que buscó solución a los problemas americanos desde la brújula socialista encendida por José Carlos Mariátegui y Víctor Raúl Haya de la Torre. Los apristas exiliados en Buenos Aires y en otras ciudades de la región, volcaron su atención hacia la revolución de 1930 en Brasil y llamaron a extender el modus operandi de las células apristas en las diferentes ciudades del país. Brasil fue otro incentivo para resignificar las decisiones que los organismos internacionales de la izquierda planteaban para las sociedades de Iberoamérica, reeditando el axioma mariateguiano: "a problemas americanos, caben soluciones americanas".

Finalmente, es destacable la exaltación de las acciones heroicas de los revolucionarios brasileños, en especial de Luis Carlos Prestes. Los discursos que sobre él se publicaron en Claridad, contagiaban 
simpatía y entusiasmo por la transformación plena del país, sobre todo al momento de definir sus ideas, la metodología a emplear y los objetivos a alcanzar. Consideraban que los años 30 y 40 del siglo XX encontraban a Brasil y al resto de los países americanos en el punto exacto de maduración que los revolucionarios habían estado esperando durante largo tiempo. Los términos de la lucha estaban planteados dicotómicamente: democracia versus autoritarismo, libre ejercicio de los derechos naturales versus censura, represión, encarcelamiento y tortura.

Desde el momento en que el director de Claridad, Antonio Zamora, se propuso publicar una revista, cuya principal función fuera mediar y promover el cambio mental en orden a la transformación social, una inquietud sobrevolaría el espíritu de los colaboradores, y se convertiría en principio de fundamentación de esta empresa editorial: ¿qué tipo de "nueva modernidad" terminaría sustituyendo el fenecido impulso de la ilustración dieciochesca? ¿Qué rol le cabría cumplir a la revista en esos tiempos decisivos?

Claridad fue concebida como un modo de interpretar el mundo social, y su reflexión endógena se entrelazó con la adaptación de nuevas formas del discurso sobre la vida social. Como hemos analizado, los autores que colaboraron con los temas políticos, sociales, económicos y culturales brasileños, habían receptado, en forma dinámica, sistemas de pensamiento y de creencias, y en ese proceso de adaptación produjeron también conocimiento. Consideramos que el corpus de textos escogidos focalizó su atención en esas figuras que fueron capaces de traducir y difundir ideas y proyectos en el ámbito local.

\section{PRESENCE AND RECEPTION OF BRAZIL IN LATIN AMERICAN PERIODICALS: THE CASE OF CLARIDAD}

Abstract: From the study of periodicals, notable source for understanding the dynamics of historical processes, we intend to define and characterize the presence and reception of Brazil in Claridad magazine, which appeared in Buenos Aires between 1926 and 1941. It notes that the Brazilian theme, in general, appeared late and was the result of interest that APRA put that country in the 1930s, when it began to accelerate social and political turbulence. Nevertheless, the "Tribuna del 
pensamiento izquierdista", as to call the director and founder Antonio Zamora, provided the space for discussion about the tensions between institutional political life of Brazil and the various revolutionary movements of those years (National Alliance liberating trabahallistas, socialists, tenentistas, communists, etc.), but still referencing both dimensions in the general context of the anti-imperialist struggles in the region.

Keywords: Brazil. Claridad. Discourse. Reception. Context's theory.

\section{Notas}

${ }^{1}$ Para un completo estudio histórico-político-ideológico de la revista, véase: FERREIRA, Florencia. Claridad y el internacionalismo americano. Buenos Aires: Claridad, 1998.

2 Waldo Ansaldi (1994) denomina "forma política de dominación oligárquica" a este período de la historia del Brasil que comprende casi desde el final de la República Velha hasta la irrupción de Getulio Vargas y su acceso al poder hasta 1945. En el período que transcurrió entre 1889 y 1930, se habían afianzado la figura de los coroneles y la institución del coronelismo y la política del café (São Paulo) com leite (Minas Gerais). Cfr. CARNEIRO LEÃO, A. El sentido de la evolución cultural del Brasil. Trad. cast. Buenos Aires: Americalee, 1945; PRADO, Caio Junior. Historia económica del Brasil. Trad. cast. Buenos Aires: Futuro, 1964; FREYRE, Gilberto. Interpretación del Brasil. Trad. cast. México: Fondo de Cultura Económica, 1945; COSTA, Cruz João. Esbozo de una historia de las ideas en el Brasil. Trad. cast. México: Fondo de Cultura Económica, 1957; SODRÉ, Nelson Werneck. Evolución social y económica del Brasil. Trad. cast. Buenos Aires: Eudeba, 1964.

${ }^{3}$ Ansaldi incluye entre los primeros a los partidarios de la revolución rusa y sus movimientos derivados, al marxismo de la Tercera Internacional; y entre los segundos a los corporativistas, los monárquicos maurrasianos y los filonazis. En estudios posteriores, el autor amplía esta interpretación recurriendo a Jorge Graciarena para diferenciar entre "crisis básica de Estado" y "crisis de la forma de Estado", siendo ésta última la característica de Brasil, pues lo que cambia es la figura de éste y se mantiene invariante, la relación fundamental de dominación. De allí que, transcurridos los años 30, se constatan líneas de continuidad en el modo de ejercer la dominación político-social bajo la forma oligárquica y en el patrón de acumulación fundado en el modelo primario exportador.

${ }^{4}$ ZAMORA, Antonio. Promesas y Realidades. Claridad, año XVIII, n. 337, 3. etapa, n. 1 , jul. 1939. 


\section{María Marcela Aranda}

${ }^{5}$ LA DIRECCIÓN. Claridad Transformará su Presentación y Contenido. Claridad, año XVIII, n. 335, (213), abr./mayo 1939.

${ }^{6}$ Las revueltas indígenas del siglo XVI; la rebelión de Cangaço, a mediados del siglo XIX, como expresión del bandolerismo social; la Guerra de Canudos (1896-1897); la Guerra del Contestado (1912-1916) son algunos de los principales antecedentes históricos de esta forma de expresión social y cultural del Brasil.

\section{Referencias}

AAVV. Reinhardt Koselleck: La investigación de una historia conceptual y su sentido socio-político. Revista Anthropos, n. 223, abr./jun. 2009.

AMADO, Jorge. Prestes: El caballero de la esperanza. Trad. cast. Buenos Aires: Futuro, 1958.

ANSALDI, Waldo. Dudas hamletianas en verde y amarillo: El ser o no ser de Brasil, 1922-1945. In: ÁLVAREZ JUNCO, José; GONZÁLEZ LEANDRI, Ricardo (Comp.). El populismo en España y América. Madrid: Catriel, 1994. p. 177-197.

. Tierra en llamas: América Latina en los años 1930. La Plata: Al Margen, 2003.

BARBOSA MELLO. Qué Pasa Actualmente en el Brasil. Claridad, año XVII, n. 324 (202), abr. 1938.

CARPIO, Campio. Interpretación del Brasil. Claridad, año XVIII, n. 335 (213), abr./mayo 1939.

CERRUTO, Oscar. Panorama Americano. Claridad, año XVIII, n. 339, 3. etapa, n. 3, sept. 1939.

COLLE, Elio. Brasil: Teatro de una Violenta Lucha Imperialista. Claridad, año XVI, n. 321 (199), enero 1938.

DEVÉS VALDÉS, Eduardo. El pensamiento latinoamericano en el siglo XX: Entre la modernización y la identidad. Del Ariel de Rodó a la CEPAL (1900-1950). Tomo I. Buenos Aires: Biblos, 2000.

FERREIRA, Florencia. Índice de Claridad: Una contribución bibliográfica. Buenos Aires: Dunken, 2005.

HEYSEN, Luis. El APRA en el Brasil. Claridad, año 9, n. 208, 14 jun. 1930. 
KORDON, Bernardo. Aspectos Históricos y Sociales de la Raza Negra en el Brasil. Claridad, año XVIII, n. 338, 3. etapa, n. 2, agosto 1939.

. Por la solidaridad con todos los pueblos y clases oprimidas del mundo.

Texto de la Conferencia de Heysen, pronunciada en el acto de adhesión a Gandhi organizado por el Ateneo. Claridad, año 9, n. 209, 28 jun. 1930.

LAFLEUR, Héctor; PROVENZANO, Sergio; ALONSO, Héctor. Las revistas literarias argentinas (1893-1967). Ensayo preliminar de Marcela Croce. Buenos Aires: El 8vo. Loco, 2006. [1968].

MANGABEIRA, Octavio. Pasado y Presente de la Dictadura de Vargas. Carta del Ex Canciller brasileño Octavio Mangabeira al Ministro de Guerra de la Dictadura de Getulio Vargas (Eurico Gaspar Dutra). Claridad, año XVIII, n. 333-334 (211-212), feb./marzo 1939.

MARTINS, Domingo José. Un Llamado a América Contra la Dictadura Brasileña. Claridad, año XIX, n. 343, tomo 19, p. 255, jul. 1940.

. La Tragedia Brasileña. La Policía de Vargas Organiza un Plebiscito Valiéndose de Medios Calcados de la Gestapo Nazi. Claridad, año XVIII, n. 341, 3. etapa, n. 5, nov. 1939.

Situación Política del Brasil. Claridad, año XVIII, n. 336 (214), jun. 1939.

MOTTA LIMA, Pedro. Qué Pasa Actualmente en el Brasil. Claridad, año XVII, n. 325 (203), mayo 1938.

NADEAU, Christian. La historia como construcción social y política: una lectura combinada de Reinhart Koselleck y Quentin Skinner. Revista Anthropos (Ejemplar dedicado a Reinhart Koselleck: la investigación de una historia conceptual y su sentido socio-político), n. 223, p. 156-167, abr./jun. 2009.

NEIBURG, Federico; PLOTKIN, Mariano (Comp.). Intelectuales y expertos: La constitución del conocimiento social en la Argentina. Buenos Aires: Paidós, 2004.

NOBLE, Cristina. Luis Carlos Prestes: El caballero de la revolución. Prólogo de Zoia Prestes. Buenos Aires: Capital Intelectual, 2007.

PRESTES, Luis Carlos. A los Revolucionarios del Brasil. Manifiesto del General Luis Carlos Prestes. Claridad, año IX, n. 219 (97), 22 nov. 1930.

. La Situación Política y Social del Brasil. La Reacción y las Fuerzas de la Alianza Nacional. Manifiesto lanzado por Luis Carlos Prestes. Claridad, año XIV, n. 294 (172), oct. 1935.

. A los Revolucionarios del Brasil. Manifiesto del General Luis Carlos Prestes. Claridad, año IX, n. 219 (97), 22 nov. 1930. 


\section{María Marcela Aranda}

SACCHI, Hugo. Prestes: la rebelión de los tenientes en Brasil. Buenos Aires: Centro Editor de América Latina, 1971.

SKINNER, Quentin. Los fundamentos del pensamiento político moderno: I. El Renacimiento. Trad. cast. México: Fondo de Cultura Económica, 1985.

. Visions of Politics: I. Regarding Method. Cambridge: Cambridge University Press, 2002.

VAN DIJK, Teun. Discurso y Contexto: Un enfoque sociocognitivo. Trad. de Andrea Lizosain. Barcelona: Gedisa, 2012.

VARGAS, Juan. Luiz Carlos Prestes: La Alianza Nacional Libertadora y la Lucha por la Emancipación del Brasil. Claridad, año XIV, n. 296 (174), dic. 1935.

VÁZQUEZ-GÓMEZ, Adolfo. A Través del Presente y del Pasado Brasileño. Claridad, año XX, n. 346, tomo XX, p. 47-50, enero/abr. 1941.

ZULETA, Emilia de. Relaciones literarias entre España y la Argentina. Madrid: Cultura Hispánica-Instituto de Cooperación Iberoamericana, 1983.

Recebido em: 12/08/2013

Aprovado em: 08/09/2013 